\title{
The use of FEA and semi-empirical equations for weight estimation of a passenger aircraft
}

\author{
Mariusz Kowalski, Zdobyslaw fan Goraj and Barttomiej Goliszek \\ Faculty of Power and Aeronautical Engineering, Institute of Aeronautics and Applied Mechanics, \\ Warsaw University of Technology, Warsaw, Poland
}

\begin{abstract}
Purpose - The purpose of this paper is to present the result of calculations that were performed to estimate the structural weight of the passenger aircraft using novel technological solution. Mass penalty resulting from the installation of the fuselage boundary layer ingestion device was needed in the CENTRELINE project to be able to estimate the real benefits of the applied technology.

Design/methodology/approach - This paper focusses on the finite element analysis (FEA) of the fuselage and wing primary load-carrying structures. Masses obtained in these analyses were used as an input for the total structural mass calculation based on semi-empirical equations.

Findings - Combining FEA with semi-empirical equations makes it possible to estimate the mass of structures at an early technology readiness level and gives the possibility of obtaining more accurate results than those obtained using only empirical formulas. The applied methodology allows estimating the mass in case of using unusual structural solutions, which are not covered by formulas available in the literature.

Practical implications - Accurate structural mass estimation is possible at an earlier design stage of the project based on the presented methodology, which allows for easier and less costly changes in designed aircrafts.

Originality/value - The presented methodology is an original method of mass estimation based on a two-track approach. The analytical formulas available in the literature have worked well for aeroplanes of conventional design, but thanks to the connection with FEA presented in this paper, it is possible to estimate the structure mass of aeroplanes using unconventional technological solutions.
\end{abstract}

Keywords FEA, Composite structures, Boundary layer ingestion, Mass estimation

Paper type Technical paper

\section{Introduction}

Air traffic is responsible for a large part of harmful gases emitted to the atmosphere; therefore, it is very important from an ecological and economical point of view to design and create effective solutions that will help to reduce the environmental impact caused by aviation. Organisations such as the European Commission (EC) put a great emphasis on the protection of the natural environment and formulate more and more stringent standards and restrictions, what accelerates the creation of new technological solutions. One of the solutions aiming, among others, to reduce fuel consumption and, hence, the emission of harmful gases into the atmosphere, is presented in the ECfunded Horizon 2020 collaborative project CENTRELINE (Seitz, 2016). Project aims to demonstrate the proof of concept for the so-called propulsive fuselage concept (PFC). The "Wake-filling" concept and its positive impact have been known for many years in the field of marine propulsion. Ship propellers are usually mounted in the aft part of the hull and operate within the boundary layer flow near the outer surface of the ship. The physical principle used in this configuration is known as boundary layer ingestion (BLI). This law is also applicable to air systems. For large commercial aircraft, the

The current issue and full text archive of this journal is available on Emerald Insight at: https://www.emerald.com/insight/1748-8842.htm

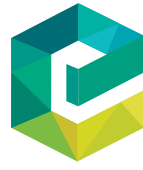

Aircraft Engineering and Aerospace Technology 93/9 (2021) 1412-1420

Emerald Publishing Limited [ISSN 1748-8842] [DOI 10.1108/AEAT-12-2020-0287] proportion of viscosity and form drag in the total drag is between $60 \%$ and $70 \%$. In the case of fuselage wake-filling propulsion arrangement, the airflow around the fuselage is ingested by a fan mounted at the rear of the fuselage. This technology allows for the drag reduction as well as the generation of additional thrust. The aircraft concept using the PFC technology is illustrated in Figure 1.

The project targets $11 \% \mathrm{CO} 2$ reduction for a PFC aircraft design against an advanced conventional aircraft with turbofan propulsion, suitable for an entry into service in the year 2035 the R2035 reference aircraft (Seitz et al., 2018a). The combination of propulsion technology with the proven tubeand-wing aircraft system builds great potential for building innovative aviation products in the future. The potential for innovation is even strengthened at CENTRELINE by

(C) Mariusz Kowalski, Zdobyslaw Jan Goraj and Bartłomiej Goliszek. Published by Emerald Publishing Limited. This article is published under the Creative Commons Attribution (CC BY 4.0) licence. Anyone may reproduce, distribute, translate and create derivative works of this article (for both commercial \& non-commercial purposes), subject to full attribution to the original publication and authors. The full terms of this licence may be seen at http://creativecommons.org/licences/by/4.0/ legalcode

This paper was written thanks to funding of the project "ConcEpt validatioN sTudy foR fusElage wake-filLIng propulsioN integration (CENTRELINE)" No 723242 funded from European Union's Horizon 2020 research and innovation program.

Received 2 December 2020

Revised 27 December 2020

Accepted 12 January 2021 
Figure 1 Turbo-electric propulsive fuselage concept (PFC) investigated in the CENTRELINE project

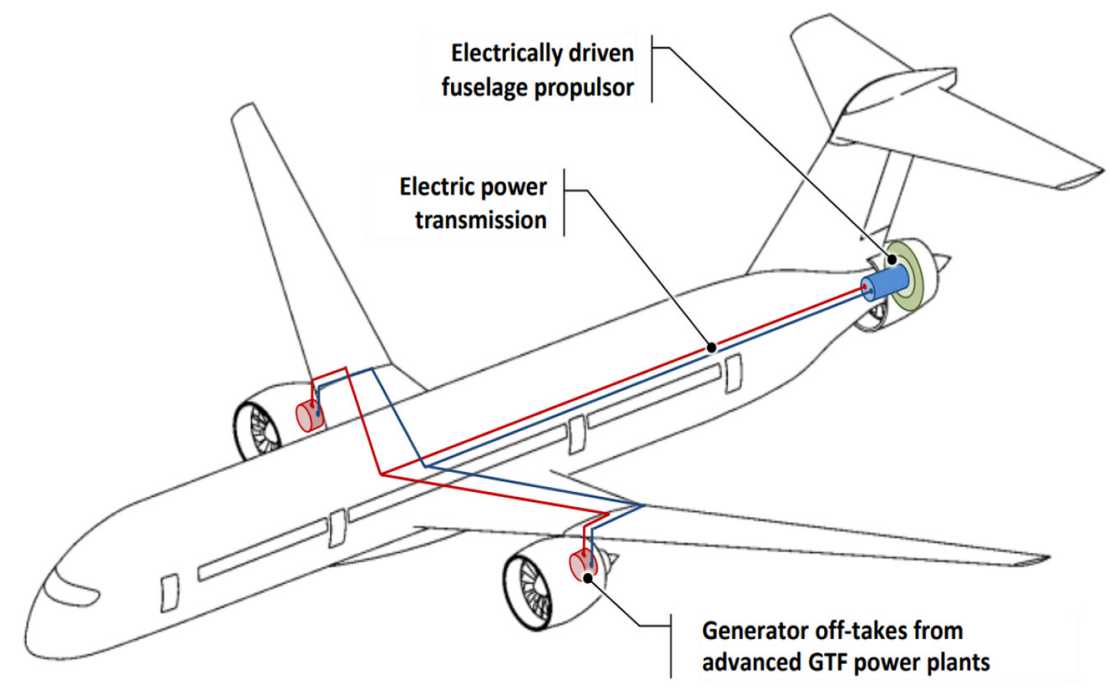

analysing and using the most advanced aerodynamic technologies as well as the most recent structural solutions.

\section{Structural activities}

As part of the CENTRELINE project, the Warsaw University of Technology was responsible for the structural integration of the propulsor mounted in the rear of the fuselage and for analysing modern structural solutions with a potentially beneficial effect on the aircraft's total mass. Evaluation of the inventive propulsion system was based on a selected R2035 reference aircraft. For the purposes of the CENTRELINE project a parametric $3 \mathrm{D}$ computer-aided design (CAD) model of the structure for the whole aircraft was created (Goraj, 2018). Model takes into account changes in relation to the conventional design of the R2035 aircraft. The main changes are related to the rear mounted propulsor. Adapting this technology enforces adjustments in the aft-fuselage load carrying structure and horizontal and vertical stabilisers arrangement. The use of the technology being the object of research within the CENTERINE project, in addition to the potential benefits brings a number of factors that can affect the final performance of the aircraft in a negative way. One of the consequences of using an additional propulsion system is the increase in weight of the load-carrying structure. This subject is investigated in the project at the Warsaw University of Technology. The prepared parametric 3D model allowed checking many different structural configurations. The parametric $\mathrm{CAD}$ representation of the initial PFC design is presented in Figure 2.

As the activities carried out within the consortium influence aircraft shaping, the prepared parametric model was a very important element affecting the efficiency of work on the concept of aircraft structure. One of the main responsibilities within the structural task was to prepare the concept of fuselage fan support structure, ensuring proper strength and stiffness while maintaining the lowest possible weight of the structure. It was assumed that the structure will be made entirely of advanced composite materials. Apart from using additional propulsion, CENTRELINE project also considers the use of other unconventional structural technologies, such as, for example, a geodetic fuselage (Goraj, 2018a). The initial structure was subjected to gradual modifications that resulted in a combination of optimal strength, stiffness and weight. In an iterative process, the structure concept with the best weight-to-strength ratio was selected, and several strength calculations were performed for the load cases identified in the CS-25 regulations (EASA, 2007).

\section{Mass estimation methods}

To evaluate the benefits that could be achieved with the fuselage BLI, it was necessary to estimate the mass penalty owing to the additional support structure needed to carry the masses and loads generated by the propulsor. As the project assumes the preparation of only the conceptual structure, it is impossible to estimate the mass only based on the CAD model because many elements affecting the final result are omitted at this early stage. Only the representation of the 3D primary-load carrying structure was prepared, so it was necessary to find a way to extrapolate the mass of this primary load-carrying structure obtained from FEA into the mass of the entire aircraft. There are numerous analytical approaches for estimating aircraft mass known in the literature, the two most popular are examined next.

Figure 2 Parametric CAD model of the initial PFC design

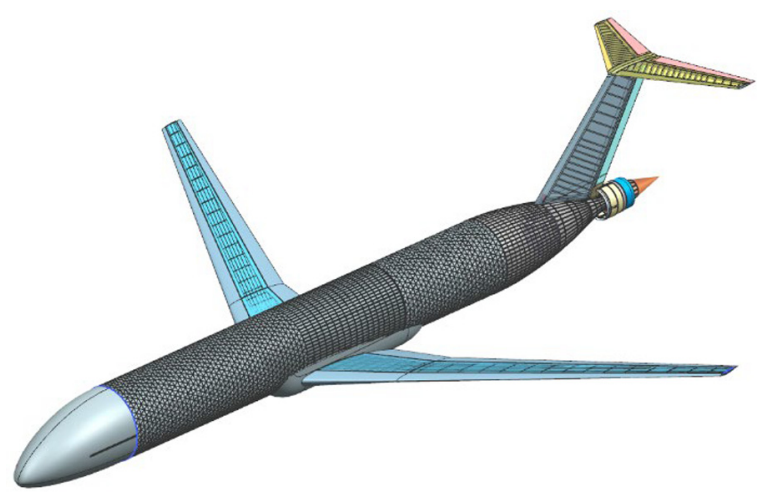




\section{Raymer method}

The method of mass estimation presented in Raymer (1992) is a statistical method based on sophisticated regression analysis. Component mass formulas do not include systems (hydraulics, anti-icing, etc.), which form separate groups, and their masses are estimated separately. Systems are not necessarily located in only one component of the aircraft, which makes it impossible to determine the total mass of individual components. These formulas also do not allow the separation of the part of the mass responsible for the primary load-carrying structure that could be replaced by the result obtained in the finite element method (FEM) analysis. The formulas below apply to metal structures; however, special factors are used to estimate the mass of the composite structure.

$W_{\text {wing }}=0.036 S_{w}^{0.758} W_{\mathrm{fw}}^{0.0035}\left(\frac{A}{\cos ^{2} \Lambda}\right)^{0.6} q^{0.006} \lambda^{0.04}\left(\frac{100 t / c}{\cos \Lambda}\right)^{-0.3}\left(N_{z} W_{\mathrm{dg}}\right)^{0.49}$

$W_{\text {fuselage }}=0.052 S_{f}^{1.086}\left(N_{z} W_{\mathrm{dg}}\right)^{0.177} L_{t}^{-0.051}(L / D)^{-0.072} q^{0.241}+W_{\text {press }}$

where:

$A=$ aspect ratio

$q=$ dynamic pressure at cruise, $\frac{l b}{f t^{2}}$

$L_{t}=$ tail length, $f t$

$N_{z}=$ ultimate load factor

$S_{f}=$ fuselage wetted area, $f t^{2}$

$S_{w}=$ trapezoidal wing area, $f t^{2}$

$W_{d g}=$ design gross weight, $l b$

$W_{f w}=$ weight of feul in wing, lb

$W_{\text {press }}=$ weight penatly due to pressurization = cabin pressure differential, psi (typically 8 psi)

$\Lambda=$ wing sweep at $25 \% M A C$

$\lambda=$ taper ratio

\section{Torenbeek method}

The mass estimation method presented in Torenbeek (2013) is a quasi-analytical method. One of the fundamental differences from the formulas developed by Raymer is the inclusion of the system weights in the individual component, which gives a chance to more precisely estimate the total weight of main aircraft parts. Another very important difference from the point of view of the analysis described in this paper is the possibility of separating the component responsible for the primary load carrying structure in the formula. In the case of Torenbeek's formulas, it is possible to replace the load carrying component with the result of an estimate based on FEM analysis. The following formulas apply to metal structures, and appropriate coefficients are used for conversion to composite structures.

$$
\begin{aligned}
W_{\text {fuselage }} & =C_{\text {shell }} d_{\text {fus }}^{2}\left(l_{\text {fus }}+l_{\text {ref }}\right)+\Omega_{\mathrm{fl}} n_{\text {ult }}^{0.5} d_{\text {fus }} l_{\text {fus }} \\
& =W_{\text {lcs }}+W_{\text {blh }}+W_{\text {sup }}
\end{aligned}
$$

where:

$$
\begin{aligned}
& \begin{aligned}
C_{\text {shell }} & =\text { calibration factor for bodies with a single }- \text { deck cabin } \\
& =60 \mathrm{Nm}^{-3}
\end{aligned} \\
& \begin{aligned}
\Omega_{f l} & =\text { calibration factor for bodies with a single }- \text { deck cabin } \\
= & 160 \mathrm{Nm}^{-2}
\end{aligned}
\end{aligned}
$$

$d_{f u s}=$ equivalent fuselage diameter, $m, \frac{\text { fuselage width }+ \text { fuselage height }}{2}$

$l_{\text {fus }}=$ length of fuselage, $m$

$n_{\text {ult }}=$ ultimate load factor

$W_{l c s}-$ weight of primary fuselage load carrying structure

$W_{\text {blh }}-$ weight of the pressure bulkheads

$W_{\text {sup }}-$ weight of other support structures

$$
W_{\text {wing }}=W_{\text {id }}+\sum \Delta W_{\text {nid }}+1.10 \sum W_{\text {sec }}
$$

where:

$W_{i d}$ - Primary wing structure weight

$W_{\text {nid }}-$ Non - ideal penalties

$W_{\text {sec }}-$ Secondary weight components

Each of the previously mentioned constituent consists of several components, and the exact methodology for their calculation is available in Torenbeek (2013).

\section{Fuselage finite element analysis}

The fuselage analysis was firstly focussed on its rear part containing the propulsor load-carrying structure and the fuselage fan (FF) nacelle (Goraj, 2019). As three power configurations are considered, separate analyses were 
performed for each configuration. The configurations differ slightly in the external geometry and the mass of the components used in the propulsor drive, hence the differences in the weight of the individual power configurations. The structure masses for the three power configurations are presented in the Table 1.

Having the detailed data on the mass of the tail section, including the FF load-carrying structure, in the next stage, analyses were carried out to estimate the mass of the whole fuselage main structure. The analyses carried out so far have proven that the use of a geodetic fuselage structure can contribute to significant weight reduction. A comparative analysis of geodetic and conventional structures is presented in (Goraj, 2018a).

In the final version of the PFC aircraft structure, the geodetic layout was used in the cylindrical parts of the fuselage, excluding the parts where the fuselage joins the wing, owing to technological difficulties in the production of such structures. The geodetic structure is, therefore, represented by approximately $60 \%$ of the fuselage surface. Similarly, a geodetic structure layout was used on the cylindrical parts of the R2035 fuselage.

The outer shell of the fuselage was modelled using twodimensional finite elements, while the reinforcing elements such as ribs, frames and stringers were modelled using onedimensional beam elements with specified cross sections. The monocoque parts of the fuselage were reinforced with frames and stringers, while the geodetic fuselage sections were equipped with hoop and helical ribs. The nodes around the fuselage-wing junction were fixed, as the calculations were focussed on the fuselage strength. The mesh was composed of 182,036 two-dimensional elements and 60,784 1D elements.

Table 1 Three power configurations aft-fuselage mass comparison

\begin{tabular}{lc}
\hline Power configuration & Aft-fuselage mass \\
\hline $5.5 \mathrm{MW}$ & $490 \mathrm{~kg}$ \\
$6.5 \mathrm{MW}$ & $646 \mathrm{~kg}$ \\
$7.5 \mathrm{MW}$ & $775 \mathrm{~kg}$ \\
\hline
\end{tabular}

Figure 3 Fuselage structure 2D element mesh

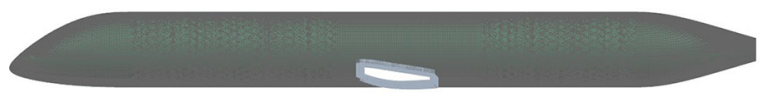

The 2D elements are shown in Figure 3, while the mesh of onedimensional elements is shown in Figure 4.

\section{Fuselage load identification}

The aircraft fuselage is subjected to numerous types of loads caused by various sources throughout its lifetime. All these loads are specified in the current CS-25 regulations (European Aviation Safety Agency, 2007). The fuselage structure must be able to withstand a variety of load limitations acting individually and in a combination. Nine critical load cases were selected and presented in the Table 2. Cases of landing loads were not analysed, as this would require a detailed design of the undercarriage attachment structure.

In accordance with applicable regulations for civil transport category aircraft in the CS25.337, a PFC aircraft will undergo maximum manoeuvres load factors of -1 to 2.5 during its lifetime.

Another unit type of load is the cabin pressurisation. The overpressure acting on the fuselage is calculated as a difference between the maximum flight altitude pressure (FL410) and the cabin pressure $(7,000 \mathrm{ft}$ altitude).

Both lateral gust loads and elevator deflection loads are important sources of stresses for the aft-fuselage structure, as because of the large arm lever, they generate relatively big bending moment. Values of these loads were derived from semi-empirical equations from (Lomax, 1996) and applied in FEM model in $1 / 4$ of MAC of VTP and HTP accordingly (Table 3).

The mass of systems and payload (Seitz et al., 2018b) was divided into 82 equal mass points, which were distributed evenly along the length of the fuselage from front to rear pressure bulkhead. The mass point representing the tail section equipped with the fuselage fan was placed in the centre of gravity of that section. All concentrated mass points were connected to the structure with RBE3 elements (SIEMENS, 2018) so as not to cause artificial stiffening of the structure. In addition to mass forces generated under the influence of overloads by concentrated mass points, as mentioned before other load sources are cabin pressurisation, lateral gust force

Figure 4 Fuselage structure 1D element mesh

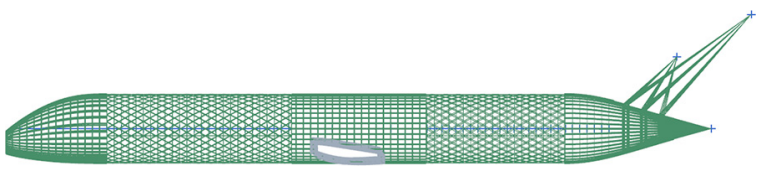

Table 2 Fuselage load cases

\begin{tabular}{ll}
\hline Case & Loads \\
\hline 1 & $1 \mathrm{G}+$ cabin pressurisation \\
2 & $-1 \mathrm{G}$ manoeuvre + cabin pressurisation \\
3 & $2.5 \mathrm{G}$ manoeuvre + cabin pressurisation \\
4 & $2.5 \mathrm{G}$ manoeuvre \\
5 & 1.33 times cabin pressurisation (over pressurisation) \\
6 & $1 \mathrm{G}+$ elevator deflection downward \\
7 & $1 \mathrm{G}+$ elevator deflection upward \\
8 & Lateral gust + cabin pressurisation \\
9 & - Lateral gust + cabin pressurisation \\
\hline
\end{tabular}


Table 3 Fuselage unit loads

\begin{tabular}{lr}
\hline Unit load & Value \\
\hline Cabin pressurisation & $60,4 \mathrm{kPa}$ \\
Elevator deflection & $172 \mathrm{kN}$ \\
Lateral gust & $161 \mathrm{kN}$ \\
\hline
\end{tabular}

acting on the vertical stabiliser and force from the elevator deflection on the horizontal tail plane. The forces are transferred to the fuselage structure through one-dimensional RBE2 (SIEMENS, 2018) elements. Figure 5 presents concentrated mass points represented by grey cubes and RBE elements shown by blue lines.

\section{Structural analysis}

In the iterative process of finite element structure analysis, a nonlinear static analysis was performed for all the load cases mentioned earlier. The purpose of the optimisation was to obtain a strength ratio (SR) (which is a safety factor equivalent in laminate analysis) as close to 1.5 as possible. It was also assumed that the displacements in the most extreme load case should not be more than $300 \mathrm{~mm}$. The structure required reinforcement in several of the most loaded areas, especially in the area of connection with the wing and in the rear part, where forces from empennage are introduced. In an iterative optimisation, the goal was to obtain satisfactory strength and stiffness, but maintaining the lowest possible weight of the structure. Figure 6 shows the SR distribution that was generated taking into account all load cases and all laminate plies. The window and door cut-outs were not included in the model of entire fuselage;

Figure 5 Concentrated mass points and RBE elements

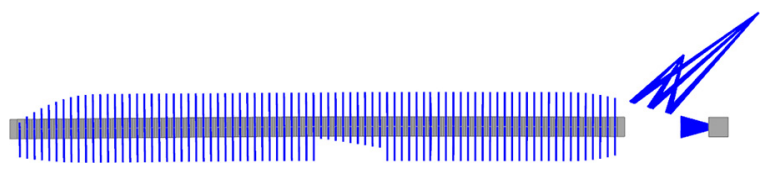

however, a side analysis has shown that such cut-outs have limited impact on the results (Goraj, 2020).

The presented SR map shows that the part of the fuselage between the wing attachment and the empennage is subjected to greater loads, which is reflected by lower values of the SR coefficient in that area. Apart from bending shear and tensile loads, the fuselage is also subjected to a torsional force caused by the empennage, that does not occur in the front of the fuselage. Figure 7 shows a displacement map for the most demanding load case (Case 3 from Table 2).

\section{Wing finite element analysis}

As part of the structural tasks within the CENTRELINE, conceptual design and initial strength analysis of the main loadcarrying structure of the PFC aircraft wing were also carried out. Analysis, similarly, to the fuselage study, lead to the estimation of the wing mass. After a twist distribution optimisation, the most extreme case of wing loading was determined and used in the finite element analysis.

A FEM mesh was prepared based on the shell model of the wing structure including the external surface, main and auxiliary spar and transverse reinforcing ribs. Skin, ribs and spar webs were modelled using shell elements, whereas spar caps were modelled with beam elements. The finite element mesh is shown in Figure 8.

\section{Structural analysis}

The iterative optimisation process ensured adequate strength, which was reflected in exceeding the SR value of 1.5. The thickness and fibre arrangement in the composite structures of individual elements were adjusted to obtain the required strength while maintaining the lowest possible weight. The most problematic zone is around the kink, where loads associated with the mounting of the main engine are introduced. The SR map for the final wing structure is shown in Figure 9.

As can be seen in the Figure 9, the most strenuous area is the zone between the spars, where SR reaches the lowest values. In

Figure 6 Strength ratio distribution for the final design
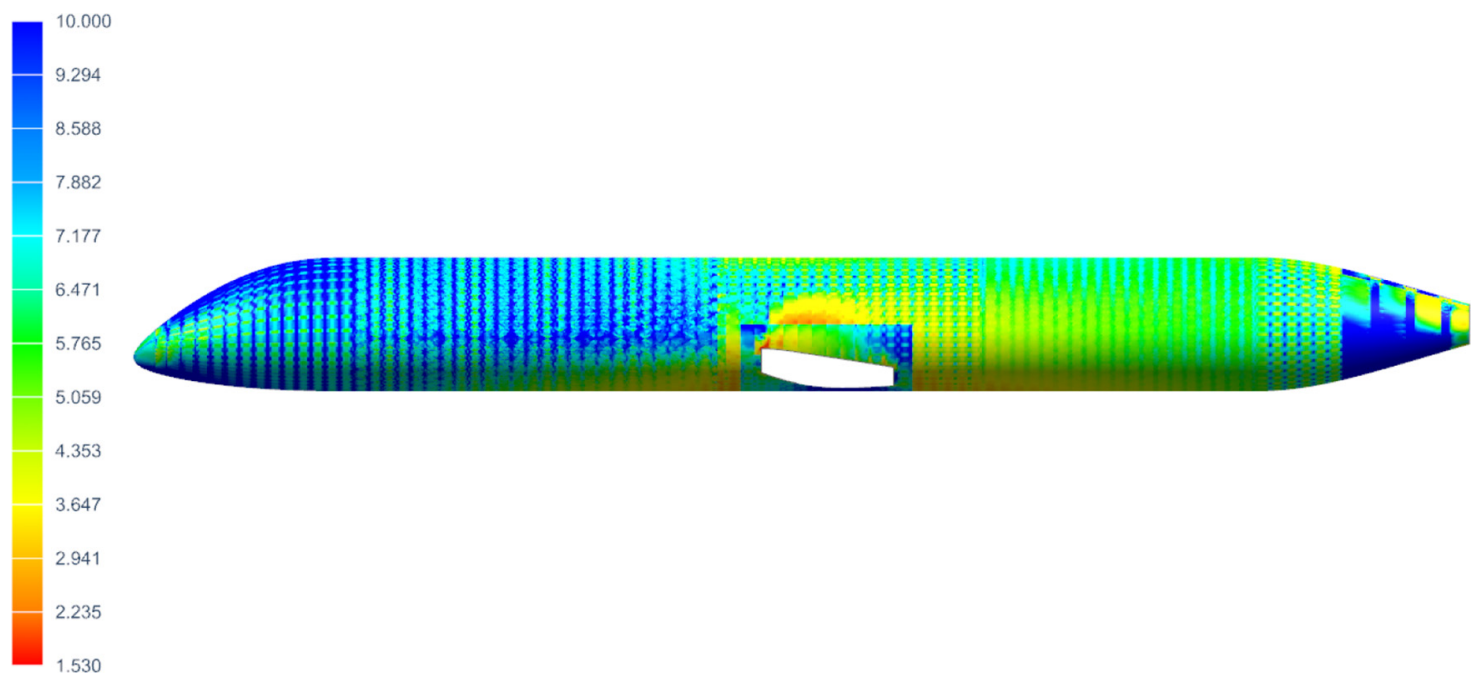
Figure 7 Displacement magnitude in millimetres for the most demanding load case

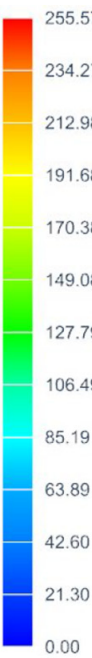

Figure 8 Wing FEM mesh

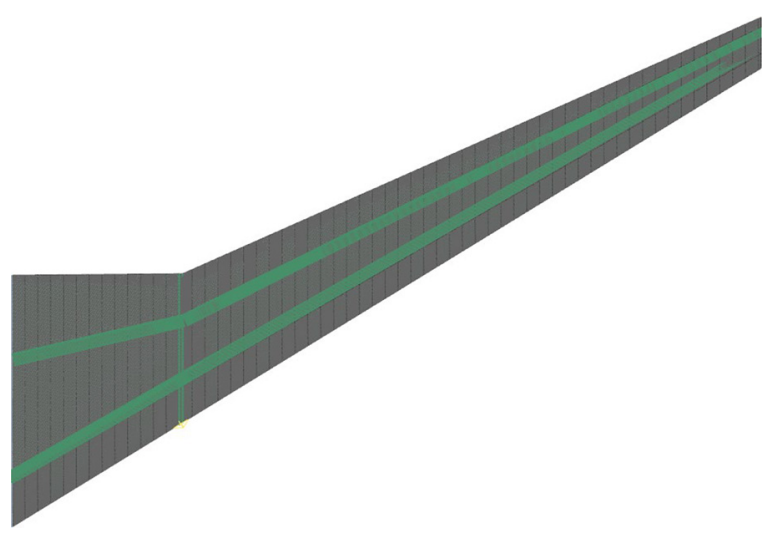

the whole structure; however, the value of 1.5 was exceeded, which ensures the safety of the structure, without causing an unnecessary increase in weight. For the described final version of the structure, the maximum displacement of the wing tip was slightly over 4.5 metres, which is a typical value for the composite aeroelastic wing. The displacement map is shown in Figure 10.

On the basis of the FEM model prepared, an estimation of the mass of the PFC aircraft wing primary structure was performed. The resultant weight of modelled part was equal to $11,415 \mathrm{~kg}$. In addition to the main wing, a separate detailed analysis was also carried out to estimate the weight of the centre-wing box. The analysis was described comprehensively in previous works (Goraj, 2020a). The calculated mass of the centre-wing box structure is equal to $2,286 \mathrm{~kg}$.

Figure 9 Wing final design SR map
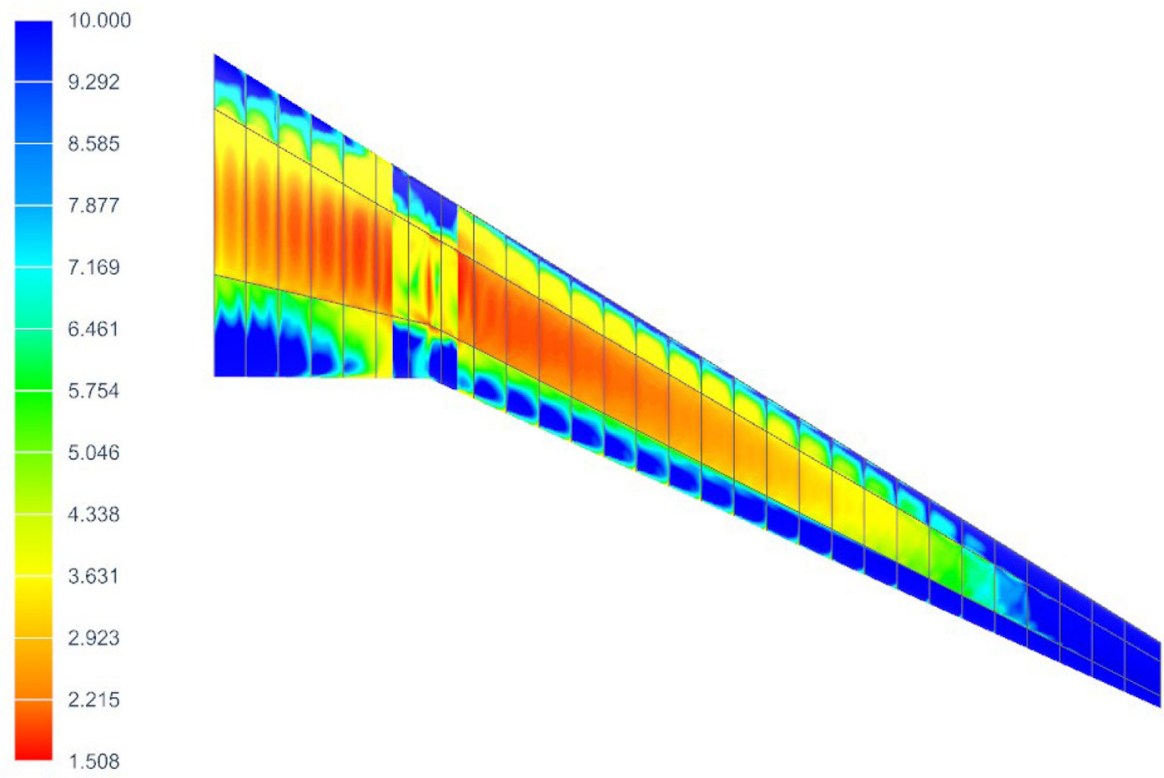
Figure 10 Loaded wing displacement map (units: millimetres)

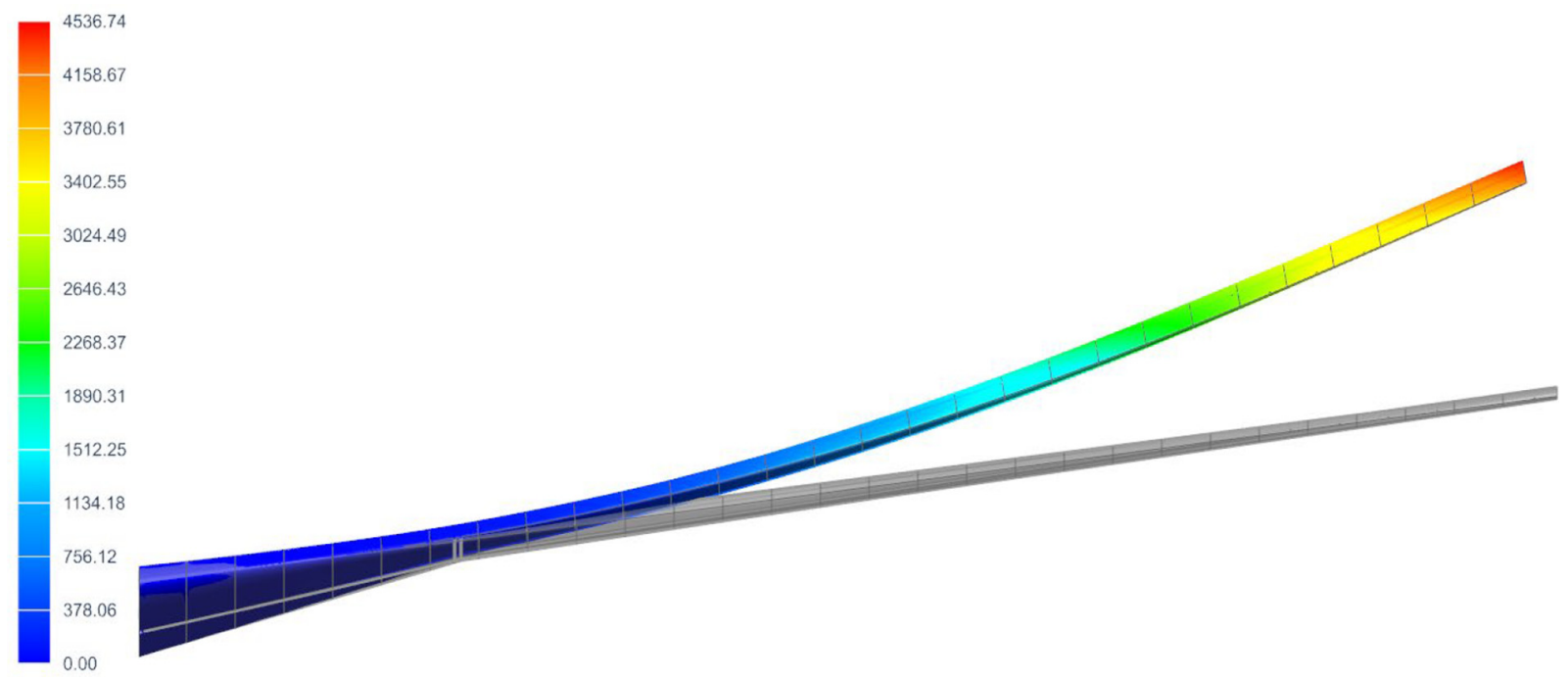

\section{Mass calculation and comparison}

Fuselage assessment

The basis for mass calculations of individual components of the PFC aircraft was the semi-empirical method formulations developed by Torenbeek (2013). As mentioned before, the equations describing the mass of the fuselage consist of three components. The first is responsible for the main supporting structure, second for the pressure bulkheads, while the third component contains all other equipment. By adding the value of the first component obtained in the FEM analysis, with the other two components calculated based on Torenbeek's formulas, the total fuselage mass of the PFC aircraft was obtained.

According to the Torenbeek method, the fuselage weight is described by the equation:

$$
W_{f u s}=W_{l c s}+W_{b l k}+W_{s u p}
$$

where $\mathrm{W}_{\text {lcs }}$ is a component describing the primary fuselage load carrying structure, i.e. skin, longerons and frames; $\mathrm{W}_{\mathrm{blk}}$ is the weight of the pressure bulkheads. In the third term of the above equation, the symbol $\mathrm{W}_{\text {sup }}$ means weights of cabin floors and floors support, doors, windows, cargo hold structures, wheel bays. The fairing around the carrythrough structure and attachment structure for the wing tail and nose landing gear are included also. Table 4 summarises all mentioned component weights for the three power configurations of the PFC aircraft.

Table 4 Fuselage components masses for three power configurations

\begin{tabular}{lrrr}
\hline & \multicolumn{1}{c}{$5.5 \mathrm{MW}$} & $6.5 \mathrm{MW}$ & $\mathbf{7 . 5 \mathrm { MW }}$ \\
\hline Component 1 & $12,242 \mathrm{~kg}$ & $12,389 \mathrm{~kg}$ & $12,527 \mathrm{~kg}$ \\
Component 2 & $282 \mathrm{~kg}$ & $282 \mathrm{~kg}$ & $282 \mathrm{~kg}$ \\
Component 3 & $10,218 \mathrm{~kg}$ & $10,218 \mathrm{~kg}$ & $10,218 \mathrm{~kg}$ \\
Total mass & $22,742 \mathrm{~kg}$ & $22,889 \mathrm{~kg}$ & $23,027 \mathrm{~kg}$ \\
\hline
\end{tabular}

An analogous analysis was carried out also for the reference aircraft R2035. The differences between the PFC aircraft and the reference aircraft are because of the lack of a tail section equipped with a fuselage fan, and the use of different empennage layout, thereby generating other forces acting on the structure. Similarly, to the PFC case, iterative repeated FEM calculations were carried out to achieve the best strength-to-weight ratio. The obtained mass of the main load-carrying structure was combined with the other two components obtained from the Torenbeek formulas. The resultant mass was used to estimate the mass penalty caused by the use of the fuselage fan. Figure 11 presents a comparison of the fuselage masses of a PFC aircraft of various power configurations with the fuselage masses of reference aircraft.

Only the empirical formulas were used to calculate the mass of the R2000 fuselage, no FEA was performed. As expected, the R2000 fuselage has of course the highest weight, while the lowest weight was recorded for the R2035 fuselage structure. However, it can also be seen that the mass disadvantage of using PFC is not very large, which bodes promising results in overall aircraft level assessment. The estimated structure mass was passed over to the aircraft level assessment of the PFC utilisation benefits.

\section{Wing assessment}

Similar to the fuselage mass assessment, the wing mass estimation was created by combining the results for the primary structure obtained in the FEM analysis with semi-empirical formulas defining the masses of the remaining wing mass components.

The wing weight is described by following equation according to Torenbeek:

$$
W_{\text {wing }}=W_{l c s}+W_{\text {nid }}+W_{\text {sec }}
$$

The first term of equation $-\mathrm{W}_{\mathrm{lcs}}-$ is the weight of primary wing structure that carries the all the wing loads, which was 
calculated using FEM model described in this report. This component summarises the masses of the wing and centre wing section.

The second term of the equation $-\mathrm{W}_{\text {nid }}-$ represents nonideal penalties:

- non-taper, joints and fasteners;

- fail safe and damage tolerance material penalty;

- engine attachment structure;

- landing gear attachment structure;

- wing-fuselage connection; and

- manholes and access hatches.

In the third term of the equation $-\mathrm{W}_{\mathrm{sec}}-$ the secondary components are included such as:

- leading edge high-lift devices;

- trailing edge flaps;

- ailerons; and

- spoilers.

Table 5 presents the summary of the wing weight breakdown in the wing baseline version.

\section{Conclusion}

In this paper the methodology was presented leading to more accurate estimation of the aircraft structure mass at the conceptual design stage, than in case of using empirical equations only. The methodology is applicable especially in case of the aircraft using unconventional structural solutions. After the introduction describing the project and its assumptions, an approach to the conducted structural analysis using the finite element method was presented. It described

Figure 11 Fuselage structures masses comparison

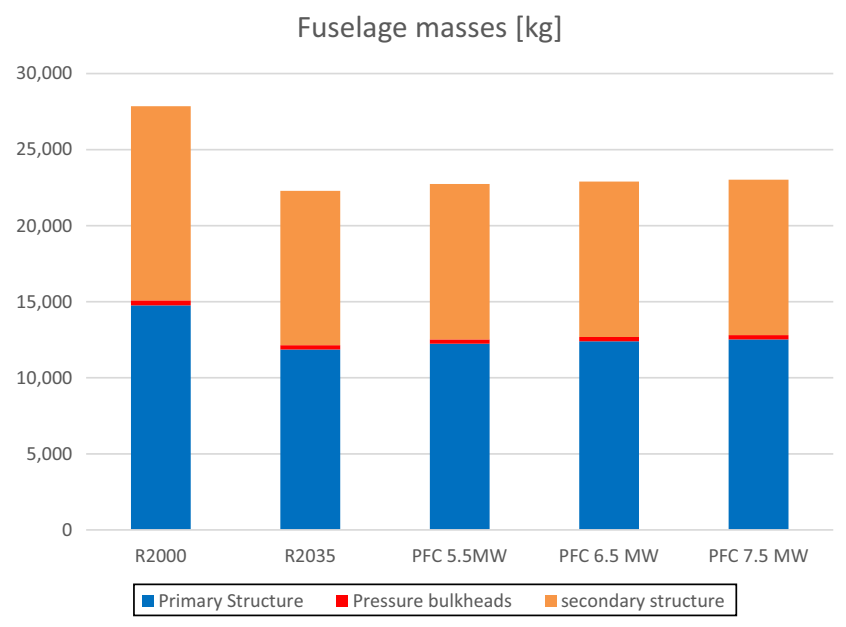

Table 5 Wing weight breakdown

\begin{tabular}{lc}
\hline Component & Weight (kg) \\
\hline$W_{\text {Ics }}$ & 25116 \\
$W_{\text {nid }}$ & 3165 \\
$W_{\text {sec }}$ & 7217 \\
$W_{\text {wing }}$ & 35498 \\
\hline
\end{tabular}

how the tested $3 \mathrm{D}$ model was created, what type of finite elements were used and how forces were introduced into the structure of the aircraft. Analytical methods of estimating the structure weight known from the literature were presented, and it was shown how these formulas can be used for a more accurate estimation combining masses calculated using FEA. The used methodology allowed for obtaining useful results that were used in the project at further stages of work, especially when assessing the benefits coming from FF application. The presented herein methodology has been applied to both the fuselage and the wing primary load-carrying structure. The described calculations have shown that because of the optimal design, increase in the mass of the structure caused by the FF installation is not as high as could be expected. The use of advanced composite materials and the optimal design of the load paths minimised the mass penalty caused by the use of fuselage BLI. By combining FEA with semi-empirical formulas, it was possible to obtain more accurate estimation of the structure mass at a very early technology readiness level than when using only available in the literature equations. The described method is obviously not as accurate as mass estimation based on an accurate CAD model containing all the parts of an aircraft, but it is incomparably less labour-intensive and can be carried out at a much earlier stage of design. The present method thus shows a reasonable compromise between accuracy and labour intensity.

\section{References}

European Aviation Safety Agency (2007), "Certification specifications for large aeroplanes CS-25".

Goraj, Z. Kowalski, M. and Goliszek, B. (2020), "Final report on fuselage and nacelle aero-structural pre-design", CENTRELINE Project Confidential Deliverable D2, p. 7.

Goraj, Z., Kowalski, M. and Goliszek, B. (2018a), "Stress, strain and displacement analysis of geodetic and conventional fuselage structure for future passenger aircraft", Aircraft Engineering and Aerospace Technology, Vol. 91 No. 6, pp. 814-819.

Goraj, Z., Kowalski, M. and Goliszek, B. (2020a), "Passenger aircraft composite centre wing box structure optimisation", 1st Aerospace Europe Conference, Bordeaux, France.

Goraj, Z., Goliszek, B., Kowalski, M., Seitz, A., Peter, F. and Meller, F. (2018), "Strategy and implementation of a parametric CAD model for R2035 aircraft structure and external configuration", 31st Congress of the International Council of the Aeronautical Sciences, Belo Horizonte, Brazil, September 09-14, 2018.

Goraj, Z., Kowalski, M. and Goliszek, B. (2019), "Optimisation of the loading structure for propulsive fuselage concept", ISABE Conference, Canberra.

Lomax, T.L. (1996), "Structural loads analysis for commercial transport aircraft: theory and practise", AIAA Education Series, 1996.

Raymer, D.P. (1992), “Aircraft design: a conceptual approach", AIAA.

Seitz, A. Bijewitz, J. Habermann, A. and Peter, F. (2018b), "Report on initial PFC aircraft definition", CENTRELINE Project Confidential Deliverable D2.10, August 2018. 
Seitz, A. (2016), “(bauhaus luftfahrt e.V.), “ConcEpt validatioN sTudy for fusElage wake-filLIng propulsioN integration (CENTRELINE)", H2020-MG-1.4-20162017: Breakthrough innovation, Proposal No.723242, European Commission Directorate General for Research and Innovation, Grant agreement number:723 242, 29 Sept. 2016.

Seitz, A., et al. (2018a), "Concept validation study for fuselage Wake-Filling propulsion integration”, Paper-ID 0382, 31st International Congress of the Aeronautical Sciences (ICAS), 09-14 September, Belo Horizonte, Brazil, 2018.
SIEMENS (2018), "Element library reference", available at: https://docs.plm.automation.siemens.com/data_services/ resources/nxnastran/10/help/en_US/tdocExt/pdf/element.pdf (accessed November 2018).

Torenbeek, E. (2013), Advanced Aircraft Design: Conceptual Design, Analysis and Optimisation of Subsonic Civil Aircraft, Wiley.

\section{Corresponding author}

Mariusz Kowalski can be contacted at: mkowalski@meil.pw. edu.pl

For instructions on how to order reprints of this article, please visit our website:

www.emeraldgrouppublishing.com/licensing/reprints.htm

Or contact us for further details: permissions@emeraldinsight.com 